\title{
Correction to: Exogenous dsRNA-mediated field protection against Pigeonpea sterility mosaic emaravirus
}

\author{
Basavaprabhu L. Patil ${ }^{1,2}$ (D) $\cdot$ Rajanna Raghu $^{3} \cdot$ Meenakshi Dangwal $^{1} \cdot$ M. Byregowda $^{3} \cdot$ Andreas Voloudakis $^{4}$
}

Published online: 25 February 2021

(C) Society for Plant Biochemistry and Biotechnology 2021

\section{Correction to: Journal of Plant Biochemistry and Biotechnology https://doi.org/10.1007/s13562-020-00627-z}

Unfortunately, the title of the article was incorrectly published in the original publication. The correct title is updated.
The original article has been corrected.

Publisher's Note Springer Nature remains neutral with regard to jurisdictional claims in published maps and institutional affiliations.

The original article can be found online at https:// doi.org/10.1007/s13562-020-00627-z.

Basavaprabhu L. Patil

basavaprabhu.patil@icar.gov.in

$\triangle$ Andreas Voloudakis

avoloud@aua.gr

1 ICAR-National Institute of Plant Biotechnology, IARI, New Delhi 110012, India

2 ICAR-Indian Institute of Horticultural Research, Bengaluru 560089, India

3 AICRP on Pigeonpea, University of Agricultural Sciences, Bengaluru 560065, India

4 Agricultural University of Athens, 11855 Athens, Greece 